Portland State University

PDXScholar

10-20-1998

\title{
Factors Affecting Methane Emissions from Rice Fields
}

\author{
M. A. K. Khalil \\ Portland State University, aslamk@pdx.edu \\ R. A. Rasmussen \\ Oregon Graduate Institute \\ Martha J. Shearer \\ Portland State University \\ R. W. Dalluge \\ Oregon Graduate Institute \\ Lixin Ren \\ Academia Sinica
}

See next page for additional authors

Follow this and additional works at: https://pdxscholar.library.pdx.edu/phy_fac

Part of the Physics Commons

Let us know how access to this document benefits you.

\section{Citation Details}

Khalil, M. A. K., R. A. Rasmussen, M. J. Shearer, R. W. Dalluge, L. Ren, and C.-L. Duan (1998), Factors affecting methane emissions from rice fields, J. Geophys. Res., 103(D19), 25,219-25,231, doi:10.1029/ 98JD01115.

This Article is brought to you for free and open access. It has been accepted for inclusion in Physics Faculty Publications and Presentations by an authorized administrator of PDXScholar. Please contact us if we can make this document more accessible: pdxscholar@pdx.edu. 
Authors

M. A. K. Khalil, R. A. Rasmussen, Martha J. Shearer, R. W. Dalluge, Lixin Ren, and Chang-Lin Duan 


\title{
Factors affecting methane emissions from rice fields
}

\author{
M. A. K. Khalil, ${ }^{1}$ R. A. Rasmussen, ${ }^{2}$ M. J. Shearer, ${ }^{1}$ \\ R. W. Dalluge, ${ }^{2}$ Lixin Ren, ${ }^{3}$ and Chang-Lin Duan ${ }^{4}$
}

\begin{abstract}
Methane emissions from rice fields are affected by a number of environmental and agricultural factors. We have analyzed our 7-year data set on methane emissions from rice fields in Tu $\mathrm{Zu}$, China, to delineate the relationships between emissions and a number of variables that were measured at the same time. Our work was done in fields that were managed under prevailing agricultural practices of the region. Consequently, only the effect of factors that vary from year to year or during the growing season can be calculated. In our study we measured the effects of environmental variables (soil temperature, wind speed, sky cover) and agricultural factors (planting density, water level, rice cultivars, organic fertilizer amounts, yield). Of these variables, soil temperature had the most significant effect on methane emissions resulting in $Q_{10}$ values of about 2 (1.5-3). The effect of sky cover, and even water levels, was to change the soil temperature, which in tum affected the methane flux. Wind tended to increase emissions, possibly by agitation of the soil. Of the agricultural variables, planting density had the most significant but complex effect on methane emissions. We studied emissions from up to 4 times the normal planting density under otherwise similar agricultural conditions in the same fields. For a four fold increase in planting density the seasonal average emissions increased by about a factor of 2 . Rice cultivars had a small but detectable effect. The amount of organic fertilizer and the yields did not affect methane emissions in our fields. The lack of an effect from the fertilizers is attributed to a saturation phenomenon whereby methane emissions do not respond to continual increases in organic material after some sufficiently high level.
\end{abstract}

\section{Introduction}

Rice fields are regarded as one of the major global sources of methane. The increase of methane during the last century, and even during recent times, is thought to be caused in part by the increase in rice agriculture [Seiler, 1984; United Nations (U.N.), 1977-1994; Khalil et al., 1996].

Many studies on methane emissions from rice fields have been reported during the last decade. The picture that has emerged is extremely complex with the rice plants integrally involved in the processes controlling the production, transport, oxidation, and the ultimate release of methane from the soil to the atmosphere [Schütz et al., 1989a; Nouchi et al., 1990]. Observational studies have produced seemingly conflicting results. These contradictions are most likely caused by our lack of understanding of the factors that control methane emissions from rice fields and the interactions between these factors, rather than the technology of the measurement process.

\footnotetext{
1 Department of Physics, Portland State University, Portland, Oregon.

2 Department of Environmental Science and Engineering, Oregon Graduate Institute, Portland.

${ }^{3}$ Institute of Atmospheric Physics, Academia Sinica, Beijing, People's Republic of China.

4Institute of Mountain Disasters and Environment, Chengdu, Sichuan, People's Republic of China
}

Copyright 1998 by the American Geophysical Union.

Paper number 98JD01115.

0148-0227/98/98JD-01115\$09.00
We conducted a detailed study of methane emissions from rice fields in China over a 7-year period between 1988 and 1994 [Khalil et al., this issue (a)]. During this study, we also measured the environmental and agricultural factors that we expected would affect methane emissions. The fields we studied were managed by local farmers according to prevailing agricultural practices and the availability of fertilizers, cultivars, and irrigation water. This causes all the factors to be effective simultaneously. We have analyzed the results and isolated some of the variables that affect methane emissions in the area we studied.

The results of this work show several important factors affecting methane emissions. Of the environmental variables, soil temperature seems to be the most significant. It appears in other guises with cloudiness and water levels in the field. Among the agricultural factors we observed that increasing planting density has a non-linear effect on the methane emissions. Other variables such as rice cultivars also affect methane emissions. However, in our case, increasing fertilizer loads or increasing rice yields did not affect methane emissions. We will document these findings here.

\section{A Survey of Factors and Their Effects}

\subsection{Database}

The measurements were taken during a 7-year experiment carried out at Tu Zu in the Sichuan Province of China. Tu Zu is a small village about $100 \mathrm{~km}$ south of Leshan city $\left(29.5^{\circ} \mathrm{N}\right.$ latitude, $106.7^{\circ} \mathrm{E}$ longitude). In this area, a single crop of rice is planted every year. Winter wheat or canola is planted for a second crop of the year, and the fields are fallow during winter. We took measurements of methane flux every other day at up to 24 plots 
with 6 plots in each of four fields. The same fields and plot locations were used throughout the 7-year period of the study.

Some 5000 valid flux measurements were obtained, more in some years, fewer in others. These measurements included morning and evening samples in all years and nighttime measurements in the later years. Most of our results will be based on the area averaged data set, which is the average over all plots sampled during the year. A single flux and a single value for the other variables are calculated for each day when measurements were taken. In all, there are data from some 400 days of sampling over the 7 -year period. For some variables, such as fertilizer use or yield, we will use the average emissions from individual fields.

Along with the flux measurements, environmental data were also collected. These data consisted of soil temperature at $5 \mathrm{~cm}$ depth, air temperature, wind velocity and direction, cloud cover, and water levels. The height of plants was measured every 2 weeks. The number of rice plants in the chamber, or the planting density, was recorded for each plot. Records were kept of type, amount, and mode of fertilizer applications, the rice cultivars planted, physical and chemical properties of the soil, and the dates of seeding, transplanting, tillering, flowering, and harvest. These primary data and the main features of the emissions are described in detail in a companion paper by Khalil et al. [this issue (a)].

\subsection{A Survey of Factors}

Using the area averaged data, we analyzed the relationships among the four variables measured at same time as the flux. There are 10 possible combinations of the variables which are $\mathrm{dF} / \mathrm{dW}$, $\mathrm{dT} / \mathrm{dW}, \mathrm{dS} / \mathrm{dW}, \mathrm{dWi} / \mathrm{dW}, \mathrm{dF} / \mathrm{dT}, \mathrm{dS} / \mathrm{dT}, \mathrm{dWi} / \mathrm{dT}, \mathrm{dF} / \mathrm{dS}, \mathrm{dWi} / \mathrm{dS}$, and $\mathrm{dF} / \mathrm{dWi}$ where $\mathrm{F}$ is methane flux $\left(\mathrm{mg} \mathrm{m}^{-2} \mathrm{~h}^{-1}\right), \mathrm{W}$ is water level $(\mathrm{cm}), \mathrm{T}$ is soil temperature $\left({ }^{\circ} \mathrm{C}\right), \mathrm{S}$ is sky cover (dimensionless units), and Wi is wind speed $\mathrm{m} \mathrm{s}^{-1}$. Air temperature was also measured, but it was found to be highly correlated with soil temperature and was not analyzed separately. For the sky cover we quantified the observations by assigning " 0 " for clear sky conditions, " 1 " for partly cloudy, "2" for overcast, " 3 " for drizzle, and " 4 " for rain. Occasionally, fog was reported, but there were not enough occurrences to evaluate its effect, if any, on methane emissions.
The data for each variable were filtered by subtracting an approximately 20-day moving average. This results in a time series without the long seasonal cycle or cycles longer than about 20 days. The mean was also subtracted from the data. This treatment serves two purposes. First, it eliminates the effect of the growth of the plants on the methane flux, as this would bias the relationships between the flux and the other variables, and second, it provides a more reliable pooling of the data from all years of observation. The pooled data can be much more powerful for finding the relationships between the variables. The filtering procedure does not substantially affect the variables for which there are no strong seasonal cycles. This was the case for most the variables other than methane flux. However, for consistency, we treated all time series in the same manner.

The filtered time series were then analyzed by two methods. First, we calculated the 10 relationships mentioned above by using linear regression between the variables. For the second method, we took the data for the numerator variable and the denominator variable and sorted it from highest to lowest values in the numerator variable. We then averaged both the numerator and the denominator variables for the half of the data with the highest values for the numerator variable and the half with the lowest values. The differences between these provide a nonregressive estimate of the 10 combinations discussed above. This method can be more sensitive than the regression method as it is a comparison of two means rather than requiring a systematic relationship over a range of values. Both methods gave similar results. The survey allows us to systematically study all the possible relationships between the variables so that the indirect effects of these variables on methane flux can be identified.

The results of the survey are shown in Figure 1, for each year when data were collected, and in Figure 2, for the composite of all years of measurements. Some patterns are apparent. The flux of methane is affected by all four variables studied, namely soil temperature, water level, sky cover, and wind. The relationships among these variables determine whether these factors are independent or driven by fewer, or even a single variable. In some cases, additional analyses of these relationships were required to better isolate and quantify the effects. We will discuss these matters further in the rest of this paper.

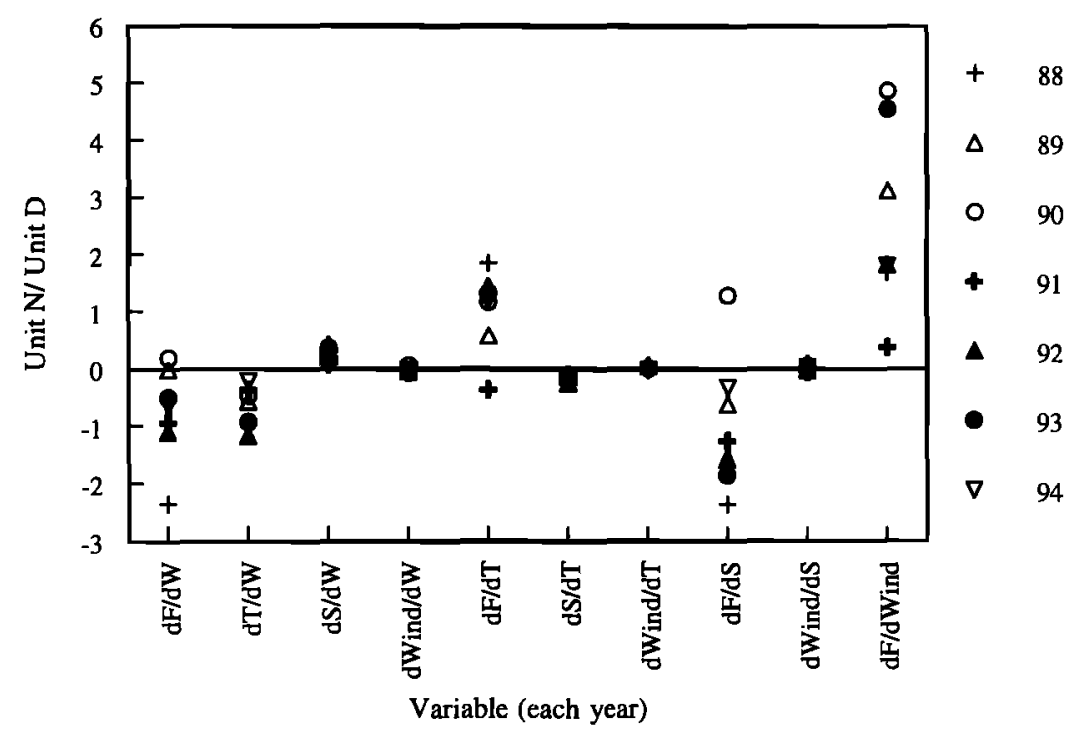

Figure 1. The relationship between methane emissions from rice fields " $F$ " and several environmental and agricultural factors. T, soil temperature $\left({ }^{\circ} \mathrm{C}\right) ; \mathrm{W}$, water level $(\mathrm{cm}) ; \mathrm{S}$, sky cover (dimensionless index); Wi, wind speed $\left(\mathrm{m} \mathrm{s}^{-1}\right)$. These results were calculated after subtracting the mean and seasonal cycle. A linear regression model was used. 


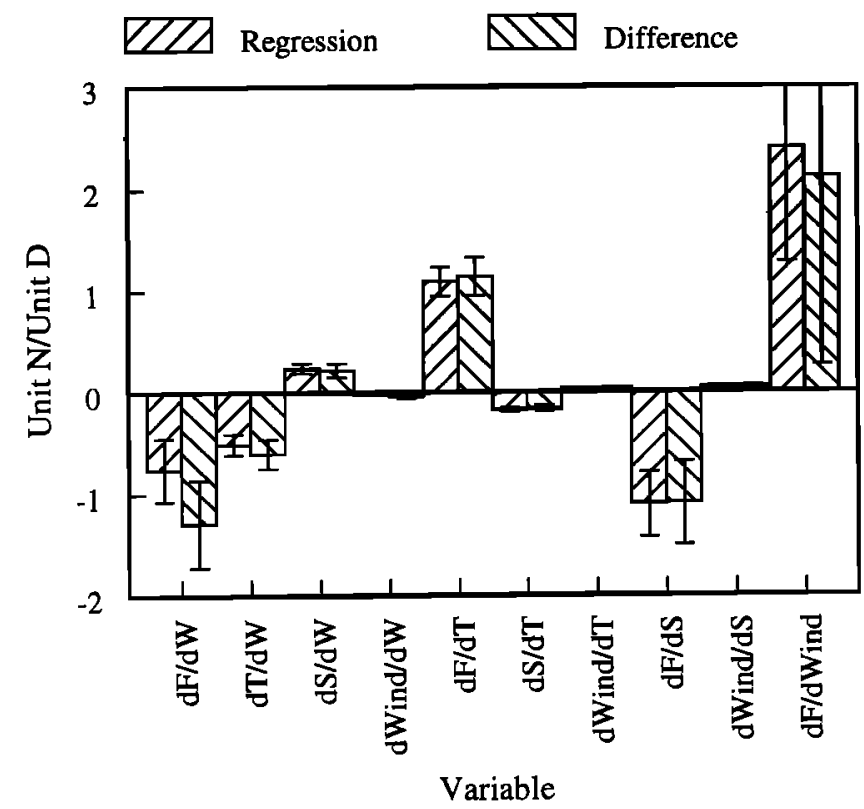

Figure 2. The relationship between methane emissions and several environmental and agricultural factors based on the composite data from 7 years of measurements. The results from two different methods of calculations are approximately the same.

\section{Environmental Factors Affecting Methane Emissions}

\subsection{Soil Temperature Effect}

It has been shown in previous studies that increased soil temperature leads to increased methane emissions [Seiler et al., 1984; Schütz et al., 1990; Sass et al., 1991; Parashar et al., 1993]. This relationship is expected because, for most biological systems, increased temperature leads to greater productivity up to some optimal temperature. While there is plenty of qualitative evidence showing that methane emissions from rice fields increase with increasing temperature, the magnitude of this response is not accurately known. Yet the magnitude is of considerable importance, not only in understanding the seasonal cycle and other variability of measured methane emissions, but also in evaluating whether there will be a substantial feedback of global warming on methane emissions from rice fields. We discuss next our results on the measurements of temperature response.

Most studies have shown that as the plants grow, methane emissions increase. This is caused in part by the increase in root surface area and in the number of tillers that in turn increase the efficiency of methane transport from the soil to the atmosphere. Other factors also influence the increased production of methane as the plants grow. At the location of our experiments, the temperature also increases after the rice is planted because the seasons change from spring to summer. Thus the temperature can increase because of seasonal change, and the methane emission may increase, at the same time, because the rice plants are growing. The increase of methane flux may not be caused by temperature increase although it may appear so. For this reason, we remove the seasonal cycle of temperature from the temperature data and the same length cycle from the flux data. The resulting time series is not affected by the seasonal processes. After filtering the data, we combined the measurements from all years and ranked them from highest to lowest flux. Then we took a 30-point moving average of both the flux and the temperature time series. The results are shown in Figure 3 on the relationship between temperature and flux. If we do not filter the long-term cycle, the relationship is even better, but it cannot be attributed entirely to the effect of temperature for the reasons just mentioned.

During the growing season, cycles of soil temperature are sometimes observed as weather systems come and go. These temperature changes affect methane emissions. Such cycles were observed most clearly in the 1988 data set. We filtered the data to eliminate all cycles greater than about 30 days and less than about 3 days (to eliminate diurnal temperature variations). The resulting time series are shown in Figure 4 for temperature and methane flux. It is clear that changes in soil temperature have a substantial corresponding effect on methane emissions. We will return to these cycles later. These are the "long-cycles" within the growing season.

In Figure 5 we show the average methane emissions during the morning and evening hours and the average soil temperatures during the same times. For these calculations the data were filtered (by subtracting a 2-point moving average) to retain only the diurnal cycles and eliminate all cycles greater than 3-4 days. This treatment does not affect the averages but only the calculated $90 \%$ confidence limits, which are shown in the figure; these are "short cycles" lasting only a day. Next we will evaluate the quantitative relationships implicit in the results shown so far.

The response of a biological system to temperature changes can be assumed to be exponential over some range around the base temperature $T_{0}$, so that flux would be

$$
F=F_{0} \exp \left[\lambda\left(T-T_{0}\right)\right]
$$

where $F_{0}$ is the flux at the base temperature $T_{0}$ and $T$ is the actual temperature. The $Q_{10}$ is then defined to be the expected flux relative to the flux at the base temperature if the temperature is raised by $10^{\circ} \mathrm{C}$ :

$$
\mathrm{Q}_{10}=\mathrm{e}^{10 \lambda}
$$

The $Q_{10}$ is a dimensionless parameter based on a simple empirical relationship that describes the change in flux, relative to the base flux, for a $10^{\circ}$ change in temperature above the base temperature. Sometimes an Arrhenius-type of expression is used to define the temperature response of the methane emissions to increased temperature, which is given by

$$
\ln (\mathrm{F})=\ln \mathrm{A}-[\mathrm{E} / \mathrm{RT}]
$$

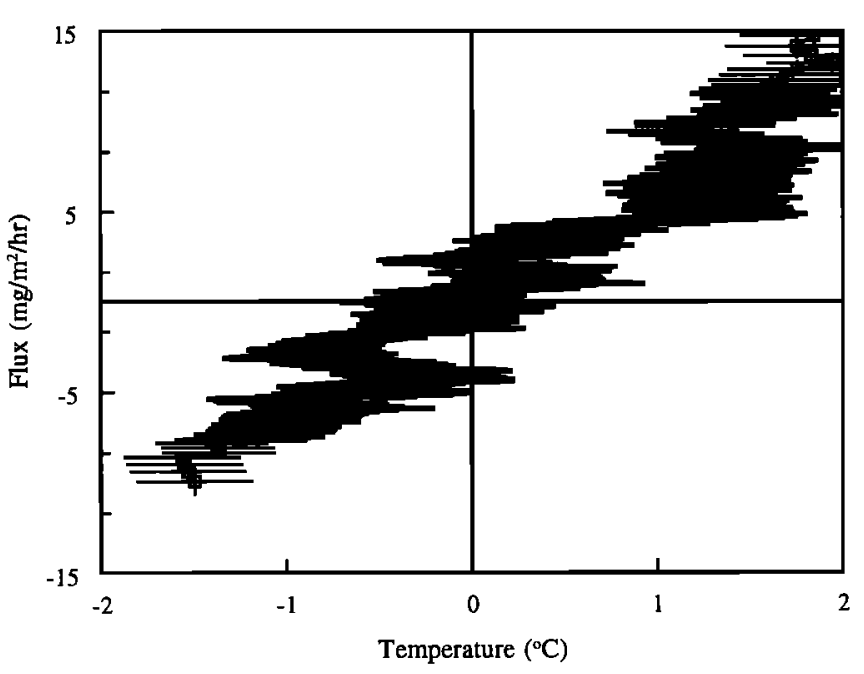

Figure 3. The relationship between soil temperature and methane flux after subtracting the seasonal cycle from the data. The horizontal bars are the standard errors of the temperature. 


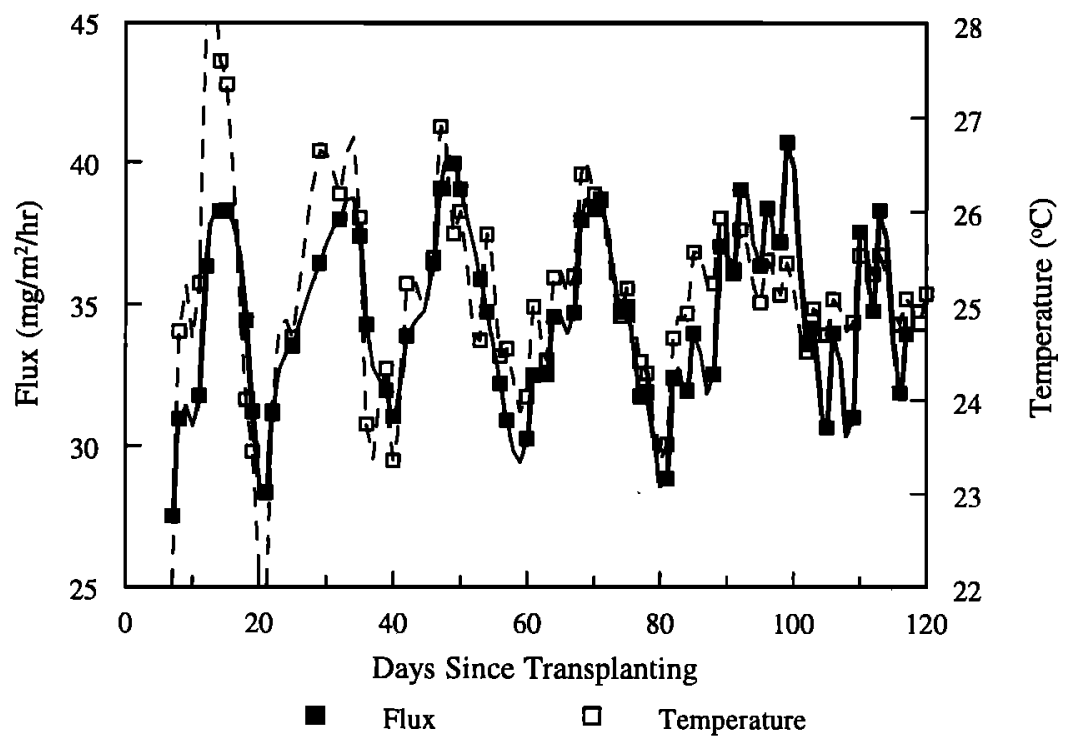

Figure 4. The relationship between soil temperature and methane flux for the long cycles of about 10-day duration. These results are from the 1988 data. Such regular cycles were not observed in other years, although irregular simultaneous variations of methane flux and soil temperature were seen in other years at similar timescales (longer than a day but less than about 30 days).

$$
\ln \left(\mathrm{F} / \mathrm{F}_{0}\right)=-\mathrm{E}_{\mathrm{a}} / \mathrm{R}\left[1 / \mathrm{T}-\mathrm{T}_{0}\right]
$$

where $\mathrm{R}$ is the gas constant and $\mathrm{E}_{\mathrm{a}}$ is some "activation energy" for the process, and $T$ is the absolute temperature $K$. $E_{a}$ defines the temperature response of the methane emissions. $E_{a}$ does not have a simple intuitive connection, and it is therefore hard to judge whether the published results are reasonable or not. For this reason, we favor the $Q_{10}$, since values greater than 3-4 are unusual for biological systems. There is a simple relationship between $Q_{10}$ and $\mathrm{E}_{\mathrm{a}}\left(\right.$ in $\mathrm{J} \mathrm{mol}^{-1}$ ) given below:

$$
Q_{10} \approx \exp \left[10 \times E_{2}(1 / R)\left(1 / T_{0}^{2}\right)\right]
$$

The measurement of the $Q_{10}$ of the rice field methane emissions is further complicated by a lack of accepted methods on what constitutes a temperature response. Often it is assumed that the diumal variability of methane emissions is caused by the diumal variability of the soil temperature [Schütz et al., 1989b, 1990; Sass et al., 1991]. This seems to be a reasonable assumption since no other mechanism has been found for the observed diurnal variability of methane flux as it seems unrelated to photolytic processes and plant respiration [Holzapfel-Pschorn et al., 1986; Nouchi et al., 1990; Denier van der Gon and van Breeman, 1993]. This is expected partly on the grounds that the methane production is below the soil where there is no direct effect from sunlight except through temperature changes, and also because methane is not emitted by the plants' stomata. Diumal variability takes place over a sufficiently short time that other factors, such as growth of the plants, do not affect emissions. We made the same assumption to calculate $Q_{10}$ s from our experiments.

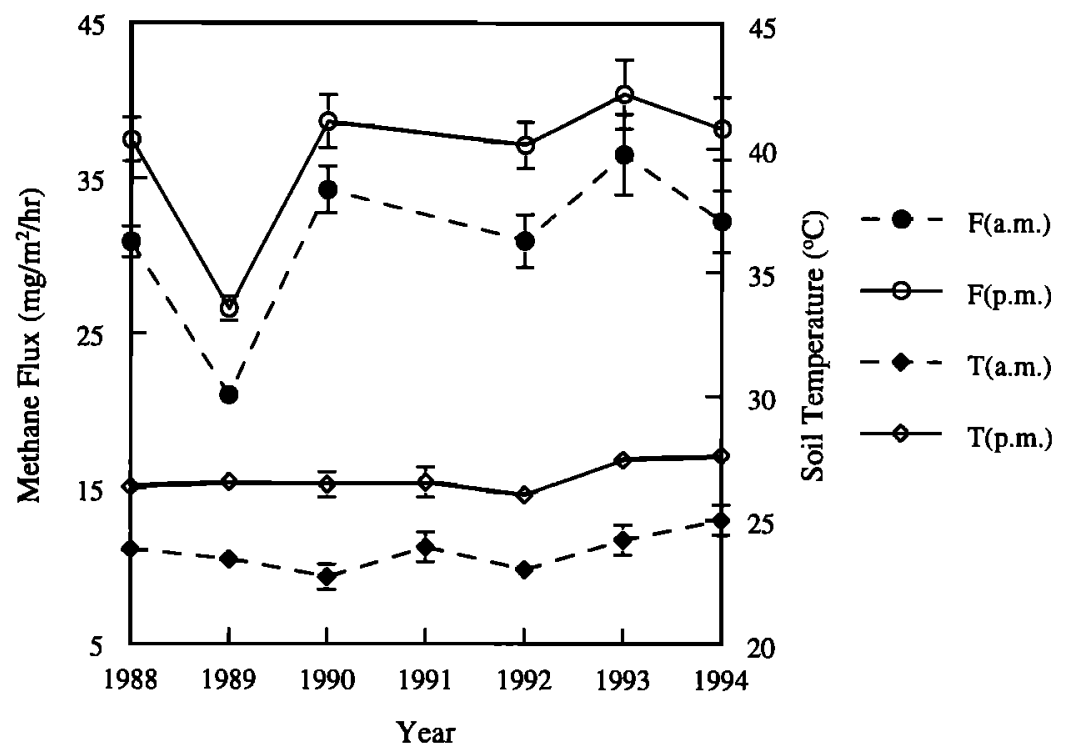

Figure 5. The seasonally averaged flux of methane from measurements taken in the moming (centered at about 0900 hours) and in the evening (centered at about 1800 hours). The averages of soil temperature are also shown. 


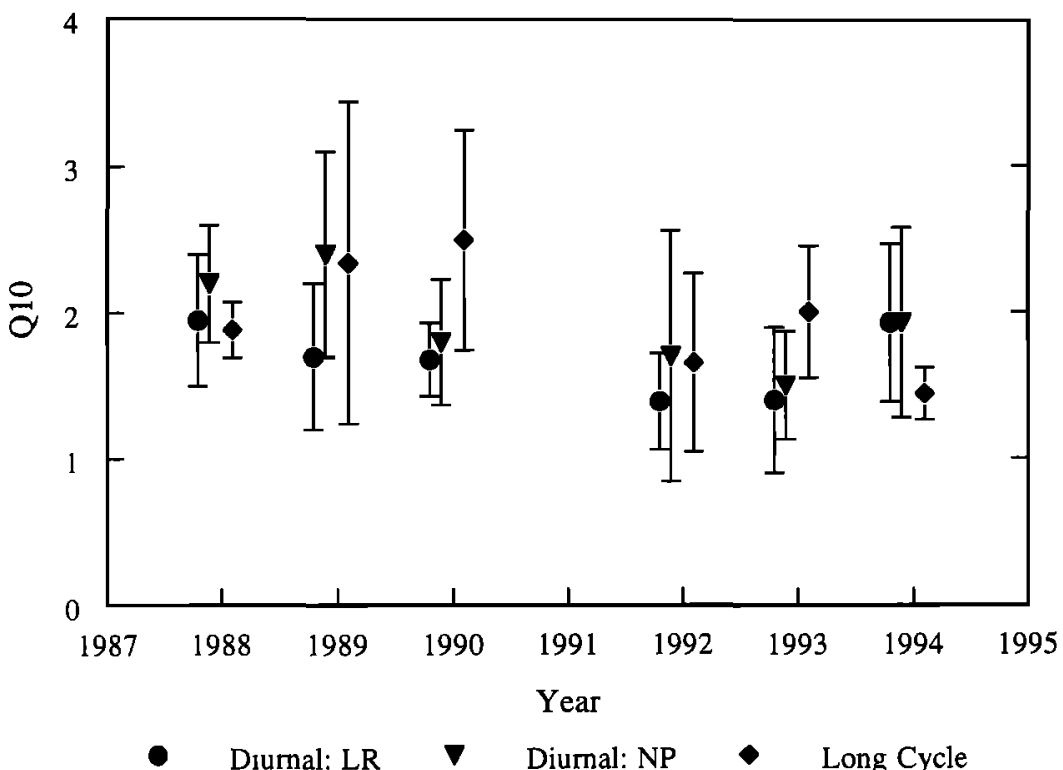

Figure 6. An estimate of the temperature response of the rice field methane emissions. The $\mathrm{Q}_{10}$ and associated $90 \%$ confidence limits are shown. Two statistical methods were used to analyze the diurnal data: linear regression and nonparametric statistics. Also shown are calculations of $\mathrm{Q}_{10}$ using regression methods and long cycle data such as shown in Figure 4.

We had pairs of measurements, one day in the morning and the next day in the evening. We calculated $\mathrm{dF} / \mathrm{F}$ as $2 \times[\mathrm{F}$ (evening) $\mathrm{F}$ (moming)]/[F(evening) $+\mathrm{F}$ (morning) $]$, and $\mathrm{dT}$ as [T(evening) $-\mathrm{T}$ (morning)]. When $\mathrm{dT}>1^{\circ} \mathrm{C}$, we took it to mean that a sufficient change of temperature had taken place that it might affect the emissions. Most of our diurnal pairs qualified under this assumption. We then calculated the linear regression (through zero) of $\mathrm{dF} / \mathrm{F}$ and $\mathrm{dT}$ to find the slope " $\lambda$ " between these two variables: $\mathrm{dF} / \mathrm{F}=\lambda \mathrm{dT}$. The $\mathrm{Q}_{10}$ is given directly by equation (1), and its uncertainty is given by the uncertainty in the slope. This method also allows us to calculate a $Q_{10}$ for each diurnal pair. These calculations are analyzed by nonparametric (nonregressive) methods to determine the best estimate of the $Q_{10}$ and its associated uncertainty as $90 \%$ confidence limits. These two methods give similar results, which are shown in Figure 6 [Snedecor and Cochran, 1989; Hollander and Wolfe, 1973]. The $\mathrm{Q}_{10} \mathrm{~s}$ are 1.5-2 or the $\mathrm{E}_{\mathrm{a}} \mathrm{s}$ are $30-50 \mathrm{~kJ} \mathrm{~mol}^{-1}$.

In some years, long cycles of temperature are observed as discussed earlier. These cycles are generally of about 10-day duration as shown in Figure 4 for 1988. These too can be used to estimate the $Q_{10}$ assuming that the simultaneous fluctuation of flux is due to the temperature changes. The calculations are based on equation (1) and are shown in Figure 6 along with the results for the short cycles. The results are similar but depend partly on the subjectivity of defining what a long cycle is, which is ambiguous, unlike the diurnal cycle. The $Q_{10} s$ are between 2 and 3 , or $E_{a} s$ are $50-80 \mathrm{~kJ} \mathrm{~mol}^{-1}$

We also addressed the questions of whether the temperature response of the rice field methane emissions changes during the growing season, or if the year-to-year changes are affected by interannual variation of temperature. We used the composite data from all years and divided it into four periods: transplanting to tillering, tillering to flowering, flowering to fruiting, and fruiting to harvest. It seems that, if there are changes in $Q_{10}$, they are small. For the interannual variations, there was no clear relationship between changes in mean temperature, which were small $\left(24.5^{\circ}\right.$. $26^{\circ} \mathrm{C}$ ), and the changes in flux, suggesting that other factors affect the interannual variability of fluxes.

\subsection{Issues Related to the Temperature Effect}

In other studies, as well as in ours, sometimes two maxima of methane flux are seen during the growing season. These are usually attributed to the supply of nutrients in the soil and to root exudation, although no evidence for these mechanisms has been presented in field studies. In the case of our experiments we saw such double maxima in only 3 of the 7 years $(1989,1992$, and 1993), and in 1988 we saw multiple maxima as shown in Figure 4. For two of the other 3 years, no double or multiple maxima were observed. In 1991 we lost a month of data in the middle of the growing season, so we cannot say whether or not another maximum occurred.

We believe that the double or multiple maxima observed in our studies were driven mostly by temperature variations on the same time scales, although other factors could also have contributed to the observed dips in the flux. We filtered the time series of both temperature and flux to eliminate all short cycles of 5 days or less. The results are shown in Figure 7. For all the years except 1993 there is evidence that the double maxima are related to temperature variations. For 1993, although there is a small dip in the temperature around the same time as the dip in flux, the relationship is not definite. The composite of all these years with the double or multiple maxima is shown in Figure 8.

If we assume that the flux changes are caused by temperature changes, we can calculate a $Q_{10}$ for just the periods when these dips occur. This calculation shows $\mathrm{Q}_{10} \mathrm{~s}$ of 4.3 (2.7-6.7), 3.1 (2.1-4.6), and $2.9(1.1-7.8)$ for 1989,1992 , and 1993, respectively, or $E_{a} s$ of $80-100 \mathrm{~kJ} \mathrm{~mol}^{-1}$. A somewhat higher $Q_{10}$ is needed to explain the relationship between flux and temperature for midseason minima compared to the $Q_{10}$ found from the diurnal variations, but the uncertainties are large. This further complicates defining a precise $Q_{10}$ for a rice field, because the time over which the temperature response occurs could also affect the result. 

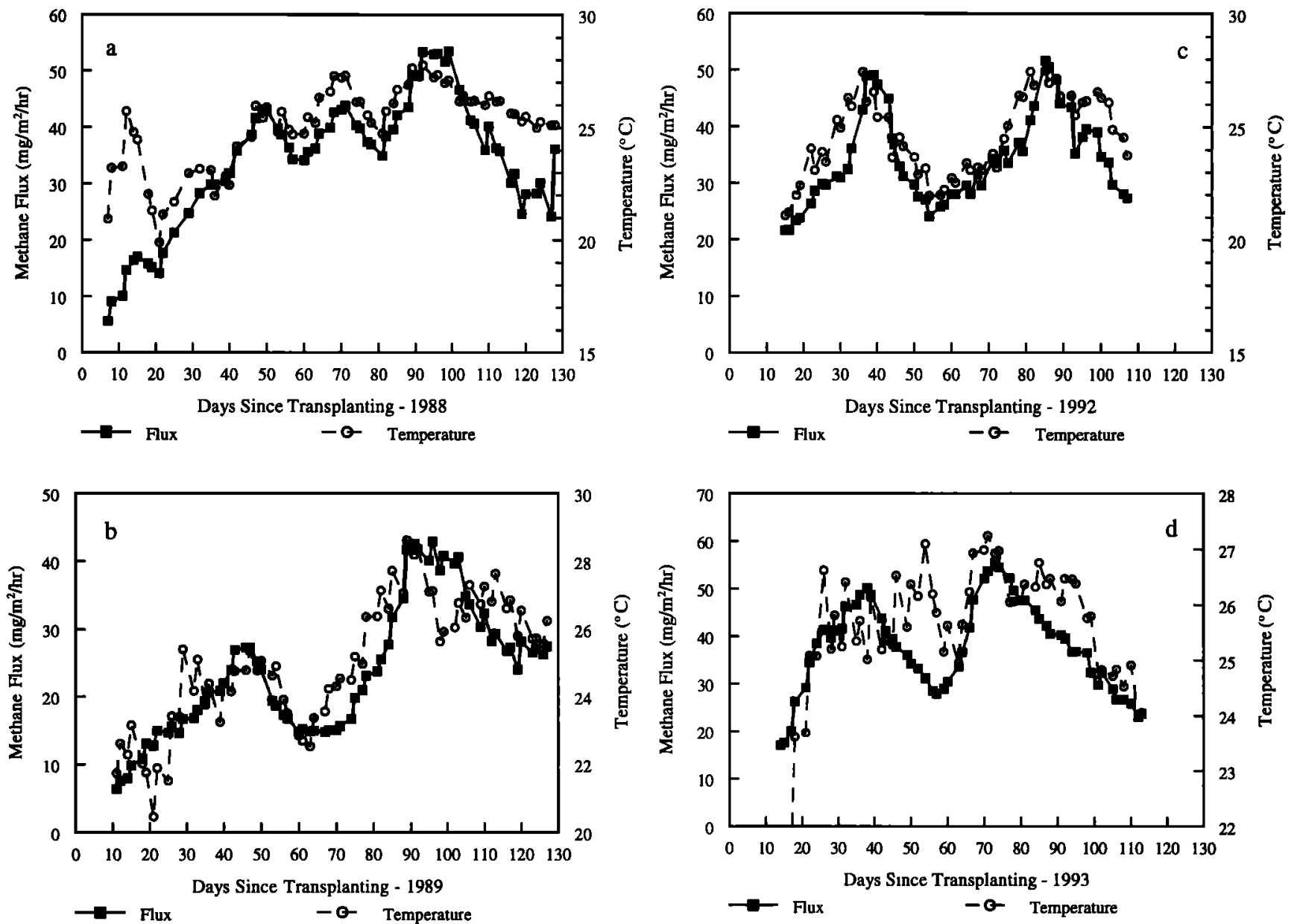

Figure 7. In some years, midseason dips in methane emissions were observed. The data on methane flux and soil temperature are shown for these years. The dips may be caused, at least in part, by the soil temperature variations on the same timescales.

There are a number of important issues in estimating $Q_{10} s$ (or equivalently the $E_{\mathfrak{2}}$ ) in field studies. Since the microbial processes for the production and oxidation of methane are below the soil, the relevant temperature is the average soil temperature at the depths where methane production and destruction take place. The temperature changes driven by the diurnal cycle of sunlight decrease with increasing depth. Therefore, if the temperature is measured deep, it would show smaller changes for the same changes of flux than if it is measured nearer the surface. The depth at which the temperature measurement is taken can thus affect the calculated

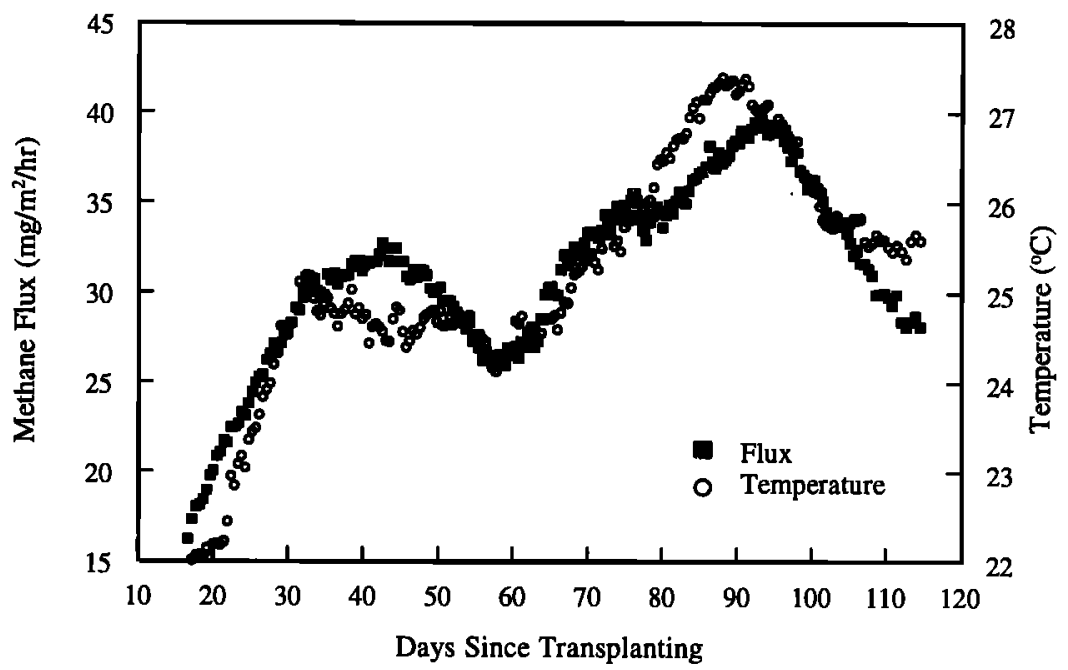

Figure 8. The relationship between the midseason dip in methane emissions and soil temperature in the composite of data from all years. An 30-point centered moving average is used to smooth the data. 
Table 1. Comparison of Apparent Activation Energies ( $\left.E_{2}\right)$ and Approximate $Q_{10}$ (Equation (5)) Calculated for Methane Emission from Rice Fields

\begin{tabular}{llcc}
\hline Study & Source & $\mathrm{E}_{2}, \mathrm{~kJ} / \mathrm{mol}$ & $\mathrm{Q}_{10}$ \\
\hline Seiler et al. $[1984]$ & field & & 4 \\
Schütz et al. $[1990]$ & field & $28-155^{\mathrm{a}}$ & $1.8-9.2$ \\
& laboratory & 41,53 & $1.7,2.1$ \\
Sass et al. $[1991]$ & field & 87 & 3.3 \\
& laboratory & $88-98$ & $3.5-4.0$ \\
Westermann $[1993]^{\mathrm{b}}$ & laboratory & 99.58 & $2.0-4.1$ \\
Yao and Chen $[1994 \mathrm{a}]{ }^{\mathrm{c}}$ & field & $12.8-247.5$ & $1.2-28.6$ \\
Yao and Chen $[1994 \mathrm{~b}]$ & field & $315.2,117.1$ & $71,4.9$ \\
Husin et al. $[1995]$ & field & $120-180$ & $5-10$ \\
\hline
\end{tabular}

\footnotetext{
"Source" indicates whether $\mathrm{E}_{\mathrm{a}}$ was calculated from soil incubations in the laboratory or measurements made during field flux studies.

From apparent $\mathrm{E}_{\mathrm{a}}$ calculated from temperature at $5 \mathrm{~cm}$ soil depth; $\mathrm{T}_{0}=17^{\circ} \mathrm{C}$.

${ }^{b}$ Calculated from alder swamp soil samples incubated for 1 day; $Q_{10} s$ (highest to lowest value) were calculated for three temperature ranges $\left({ }^{\circ} \mathrm{C}\right): 15^{\circ}-35^{\circ} ; 20^{\circ}-30^{\circ} ; 25^{\circ}-35^{\circ}$.

${ }^{c}$ Soil temperature measured at $1-2 \mathrm{~cm}$ depth; $\mathrm{T}_{0}=25^{\circ} \mathrm{C}$.
}

$Q_{10}$. To ensure that the temperature is determined at the correct depth requires additional measurements. Schütz et al. [1989a] calculated the correlation coefficients of the temperature at various depths with the flux. The depth that showed the highest correlation was taken as the appropriate location for the temperature measurement to calculate the $Q_{10}$. This depth of maximum correlation was not constant over the entire growing season. Other studies have not stated precisely whether there is evidence that the depth of the temperature measurement is indeed the location of the microbial activity responsible for the emission of methane from rice fields. This makes it difficult to decide whether the different studies are measuring the same parameter or not.

The $Q_{10} S$ we have estimated are in the same range as many other studies (Table 1). The causes for the differences are not always apparent, though soil depth of temperature measurements, and base temperature $\left(\mathrm{T}_{0}\right)$ can affect the comparisons.

In some studies, such as the work in Indonesia or Yao and Chen in China, the changes of flux between morning and evening are quite large. It was recognized by Conrad et al. [1987] that the observed effects may not be explainable entirely on the grounds of increased methane production by methanogens. Pure strains of methanogens have $Q_{10}$ responses around 2 or $E_{a}$ of $50 \mathrm{~kJ} \mathrm{~mol}^{-1}$ [Conrad et al., 1989]. Much higher $\mathrm{Q}_{10} \mathrm{~s}$ require further explanation.

The $Q_{10}$ observed is potentially a product of several $Q_{10} S$, one each for the processes involved in the production, oxidation, and emission of methane. If the flux is a function of several variables, $\alpha_{i}$, all dependent on soil temperature: $F=F\left[\alpha_{1}(T)\right]$, then

$$
\begin{gathered}
Q_{10}=\prod_{i=1}^{N}\left[Q_{10}\left(\alpha_{i}\right)\right]^{a_{1}} \\
a_{i}=\frac{\alpha_{i}}{F} \frac{\partial F}{\partial \alpha_{i}}
\end{gathered}
$$

Here $a_{i}$ is the relative response of the flux to changes in the process $\alpha_{i}$. These fundamental processes determine the $Q_{10}$ that is actually observed. Such processes can either amplify or attenuate the basic $\mathrm{Q}_{10}$ of the methanogens. For instance, if twice as many methanogens produce twice as much methane, then the " $\mathrm{a}$ " for this process in equation (7) would be 1 , and the observed $Q_{10}$ would be the same as the $Q_{10}$ of the methanogen populations, assuming all other factors can be neglected. In this case " $\alpha$ " would be the methanogen populations (P), and according to equation (7), a * $(\Delta F / F) /(\Delta P / P)=1$. If, to take another example, methanotropic bacteria also increase with increasing temperature and oxidize more methane, the "a" for this process in equation (7) would be negative and the observed $Q_{10}$ would be attenuated relative to the $Q_{10}$ of the methanogens alone (the $\alpha$ for this example is the populations of methanotropic bacteria). Clearly, there are many factors that affect the temperature response that is observed. In most cases the variables affecting the observations of $Q_{10}$ are hidden, making it difficult to define a $Q_{10}$ for rice fields as a whole. These complexities also make it difficult to credibly assess changes of methane emissions in a warmer world; to use soil temperature as a means for extrapolating measured fluxes to larger regions; or to explain the differences of fluxes from different parts of the world.

\subsection{Wind and Cloudiness}

As before, we filtered the flux and soil temperature data, using a moving average filter to eliminate the long-term seasonal variations of about 20 days or longer, which in the case of these variables does not have a major effect. We then sorted the resulting deseasonalized time series of flux and temperature according to sky conditions. We divided the data into two categories: when the sky cover index was greater than 2, representing full cloud cover, drizzle, and rain; and when the sky cover index was less than 2, representing partly cloudy or clear conditions.

The results of these calculations are shown in Figure 9a for the change of flux and temperature per unit change in sky cover. For almost all the years of the experiment, the flux decreased with increasing cloud cover. This does not mean, however, that solar radiation increases methane emissions. Increased solar radiation also increases soil temperature as is shown in Figure 9b, which could in turn increase emissions by the temperature effect discussed earlier. In fact, the $Q_{10} s$ necessary to completely explain the observed increase in flux, with increasing soil temperature that accompanies the increase in solar radiation, are between 1.5 and 3 , which is well within the range determined earlier. The exception to the patterns is in 1990 when no significant temperature difference was observed with changes in sky cover, and also no change was seen in the methane flux with sky cover. In 1990 we lost a month of data from the middle of the growing season, which contributed to this result. 

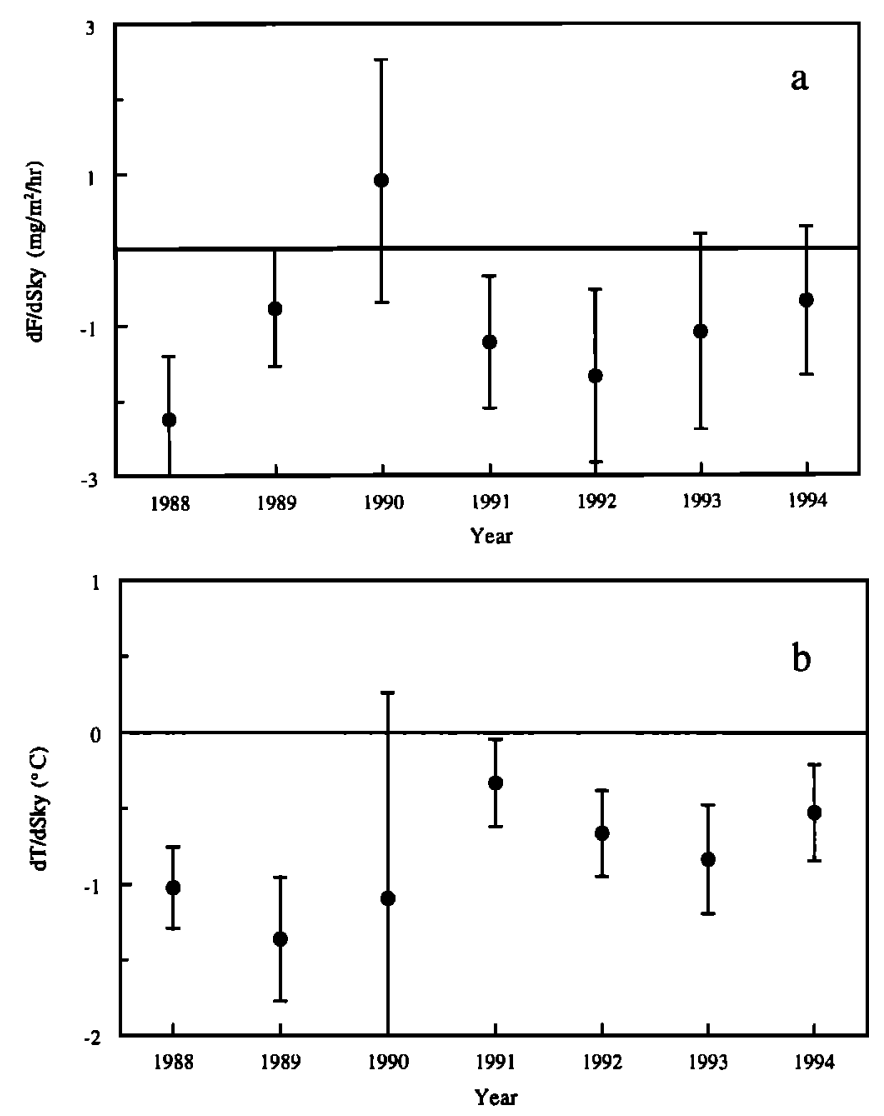

Figure 9. The relationship between sky cover, soil temperature, and methane flux. The results suggest that cloudiness lowers soil temperature thus reducing methane emissions. It acts indirectly to affect methane emissions.

In 1993 and 1994 we have about half as much data as in other years because half the measurements were done during nighttime. The nighttime measurements have not been included in the results shown in the figures. An analysis of the nighttime data shows that there was no statistically significant difference in soil temperature or the methane flux when the skies were clear and when there was rain and cloudiness as separated by the sky cover index of greater than or less than 2.

Greater wind speeds tend to result in greater methane emissions. For 1991, 1993, and 1994 there are very few cases when a nonzero wind was reported, which reduces the number of effective observations available. The wind is not related substantially to any other variable although it tends to be higher with higher temperature, which could contribute to some of the observed relationship. Wind can affect fluxes from rice fields by increasing the agitation of the soil and water as the plants are moved by the wind. This effect may be larger in windier locations.

\section{Agricultural Factors Affecting Methane Emissions}

Agricultural practices can have a major effect on methane emissions from rice fields. The effects of fertilizers, water management, and cultivars were evaluated in our research.

\subsection{Planting Density}

The rice plants have an important role in the exchange of methane between the soil and the atmosphere. The plants are involved in three processes that affect methane emissions. The plants act as conduits for methane transport, the root zones create conditions for oxidation of the methane that is produced so that only some fraction escapes, and the roots may exude organic compounds that can be utilized by methanogens to produce methane. These processes create a complex relationship between planting density and methane emissions. If there was no oxidation in the root zone, the effect of planting density would only manifest itself in the additional production of methane because of more root exudation. The additional transport from more plants would not affect the total amount of methane released during the growing season but may slightly modify the seasonal pattern of emission. If there is no production of methane from root exudation, then more plants per unit area would reduce the residence time of methane in the soils by causing more rapid transport between the soil and the atmosphere. This would increase the emission of methane, because less would be oxidized, even though the production may not have changed. The volume of the root zone where methane is oxidized increases with planting density, but the flux is also likely to be proportional to volume of the root zone, thus canceling this effect. The effect of planting density is to increase methane emissions, but the actual magnitude of the increase is complicated by the three processes discussed here. Four times the normal planting density does not produce 4 times the methane emissions, and the interactions of these processes do not produce a uniform change of methane emissions throughout the growing season. Here we will document the observational evidence for the effect of planting density on methane emissions. These processes are discussed more quantitatively by Khalil et al. [this issue (c)]

In our experiments, aluminum bases, enclosing an area of 562 $\mathrm{cm}^{2}$, were embedded into the rice fields before the rice was planted. The bases included a lip that penetrated into the top soil. The bases were further stabilized by stakes driven into the clay below the top soil. One, two, or four rice seedlings were planted inside the bases. If there were four, they were planted at the edges, and if there was one it was in the middle. The distance between the plants, even in the case of four plants per plot, were about the same as the distances between plants in the rest of the field. So, one to four plants could easily been grown inside the bases. Because of the permanent base, when there were four plants per plot, the tillers could not grow outside the base which created a much higher density of tillers than in the field. The tillers instead of expanding in all directions were directed towards the center of the base, covering most of the area inside the base. The roots are expected to have followed the same path and be most concentrated for the four plant plots. The lip penetrating below the soil also provided a barrier for the top of the roots preventing expansion outside the confines of the base as lateral spread is common [see Grist, 1986]. These conditions create a high density for the four plant plots compared to one plant plots, that are considered to be representative of the prevailing planting density of the field. These matters are discussed in more detail by Khalil et al. [this issue (c)]. On the basis of data obtained in earlier years, in 1992, we designed experiments to systematically study and quantify the effect of planting density. The results showed a complex relationship between emissions from plots with one plant compared to plots with two or four plants.

On the basis of many observations in the fields we estimated that the average distance between plants was about $20 \mathrm{~cm}$. This distance seems to be common in many of the fields we have studied, not only in the $\mathrm{Tu} \mathrm{Zu}$ area but also in Guangzhou and Indonesia where we have done similar experiments [Husin et al., 1985; Khalil et al., this issue (b)]. We determined that for the small chambers used between 1988 and 1994, one plant in the chamber was within $10 \%$ of the prevailing planting density of rice in the fields at $\mathrm{Tu} \mathrm{Zu}$. The one plant plot became our standard for representing the emissions 


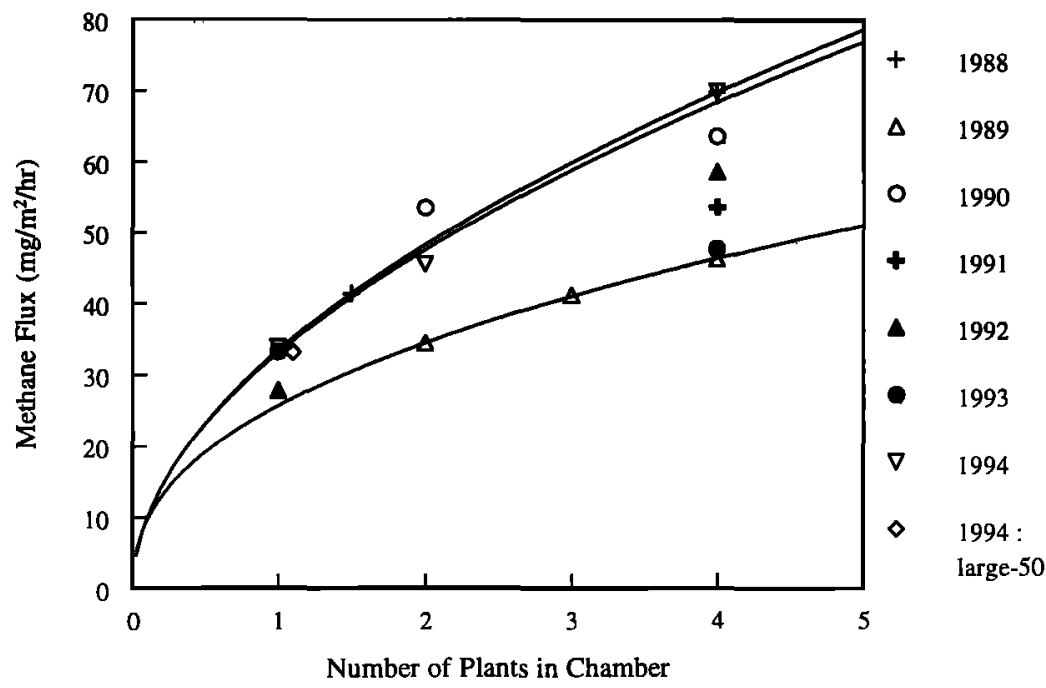

Figure 10. The effect of planting density on methane emissions from rice fields. Plots of 1, 2, 3, and 4 plants in the same area show increasing emission rates. The prevailing planting density in these fields is about one plant per plot for our sample plot size.

from the fields. This planting density was verified by using much larger chambers that have up to 50 rice plants inside at the prevailing density of the fields. The emissions measured from these large chambers and the emissions measured with the one plant small chambers placed inside the large chambers gave almost the same results [Khalil et al.,this issue (a)]. Using this standard, we can determine the effect of increasing planting densities at twice and 4 times the normal density.

The effect is shown in two figures, both of which are based on many plots in each category and several years of observations. Figure 10 shows the average fluxes observed for the plots with one two, or four plants. There is considerable interannual variability in the response of the rice fields to planting density, but generally the four plant plots produce about twice as much methane during the growing season as the one plant plots. For comparison, we also show the large chamber results in 1994 with about 50 plants and three replicates. These large chamber studies reflect the effect of prevailing planting density of the fields, which, as mentioned earlier, is about the same as for one plant per small plot using the small chambers. Figure 11 shows how the emissions respond to planting density during the growing season. We took the data from the years when we had cases with one plant per plot and with four plants per plot (1988, 1992-1994). A composite data set was created as a function of days since transplanting. Then we took an 11-point centered moving average of the time since transplanting and the flux data from one and four plant plots. The (11-point) window length for the moving average is arbitrary but not important to the discussion here. The results show that the difference is smaller in the beginning and toward the end of the growing season compared to the middle of the season. Since the differences

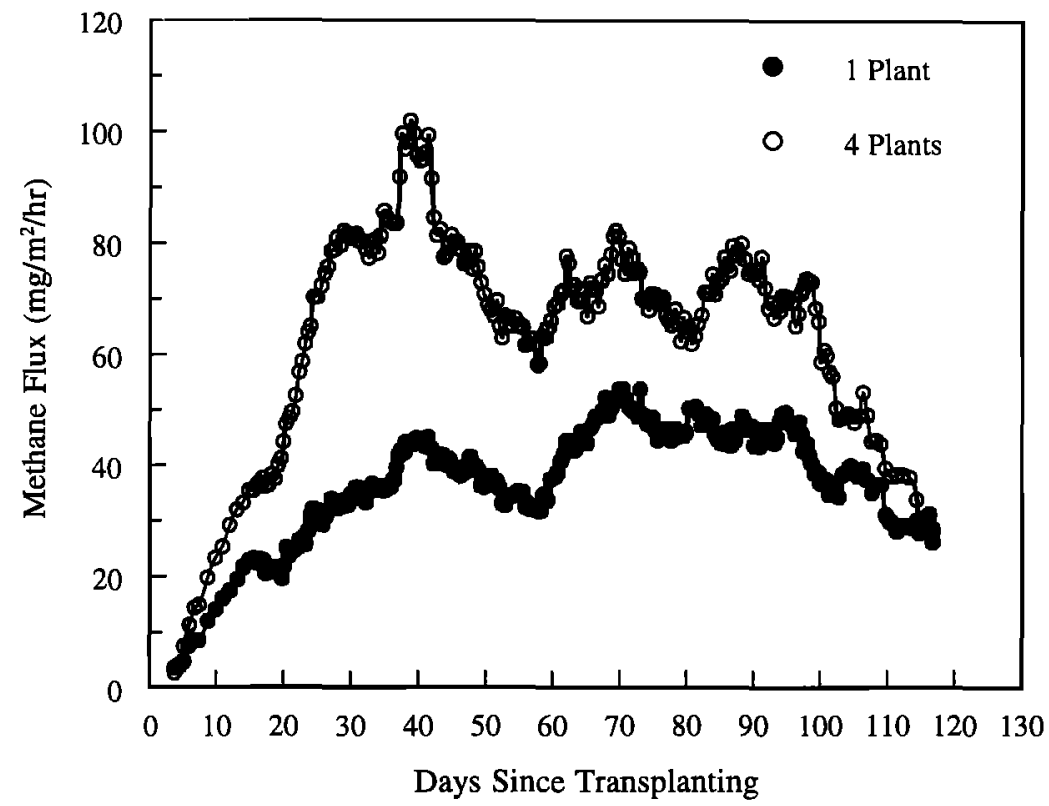

Figure 11. The effect of planting density on methane emissions from rice fields during the growing season. The data used are for the years when one plant per plot and 4 plants per plot measurements were made. This shows the most extreme effect and spans from the prevailing planting density to about 4 times the density. 
between one and four plant plots are only about a factor of 2 at most, to a first approximation, the effect of two plants or three plants in a plot can be interpolated by using Figure 11 .

We can explain these results theoretically, though qualitatively, as follows. In the early part of the growing season the plants are not effective at transporting methane and the root zone is small so that neither root exudation, nor oxidation processes are effective. The emission of methane is mostly controlled by ebullition, which is more or less independent of the planting density [Schütz et al., 1989a]. Hence the emissions are about the same whether there are four plants in the plot or just one. In the next phase of growth, as the plants tiller and grow vigorously, all the processes mentioned above may be active. There could be enhanced production of methane because of root exudates from more plants and faster transport that reduces the net oxidation. This stage has the greatest effect from planting density. Emissions from four plant plots are 23 times as high as emissions from one plant plots. In the next stage, as the plants mature and flower, there is no further increase of transport efficiency, and root exudation is greatly reduced as the roots are then fully grown [Hale and Moore, 1979; Minoda et al., 1996]. Other substrates for methane production may also be exhausted. At this stage, therefore, the number of plants per unit area does not affect methane emissions as much as before because the flux is limited by production and not the transport. The presence of fast transport after tillering keeps the concentration of methane in the soil low enough that bubbles are not formed, and plant mediated transport is the major pathway for transferring methane to the atmosphere [see Khalil et al., this issue (c)].

\subsection{Water Levels}

The effect of water level on methane emissions was first reported by Sass et al. [1992] and Chen et al. [1993]. These studies showed that when water is allowed to evaporate during the growing season and an intermittent flooding schedule is adopted, methane emissions are greatly reduced compared to the conditions when the fields are inundated during the entire growing season. The results of these studies are an important discovery regarding the factors that effect methane emissions from rice fields and the potential for controlling these emissions, if appropriate, to reduce global warming. The effect has since been observed in other studies by Husin et al. [1995], Yagi et al. [1996], and Khalil et al. [this issue (b)].

We studied fields under prevailing agricultural practices of the region. In the area of our study at $\mathrm{Tu} \mathrm{Zu}$, fields are kept inundated throughout the growing season. The water levels in the fields we studied did change during the growing season and from year to year, but the fields always had several centimeters of water at all times. In Figure 12a we show the relationship of the methane flux and water level, with each point representing a different year. These were calculated according the procedures described in section 2.2. The data were filtered to remove all cycles of 20 days or longer, and the mean was subtracted to be able to compare the results from different years. Figure 12a shows that in almost all years, methane flux was inversely related to water level. More water resulted in less methane emissions. There is no contradiction between our results and the previous studies, however, because in our experiments water was always present.

The relationship between water level and methane emissions may be due to changes in soil temperature. We noticed that higher water levels resulted in lower soil temperature as shown in Figure 12b, which would explain the lower methane emissions. The magnitude of the effect can be accounted for by a $Q_{10}$ of between 1.5 and 2 , which is well within the range determined by diurnal variations of flux and other procedures discussed in section 3.1. The observation that higher water levels come with reduced soil temperature was
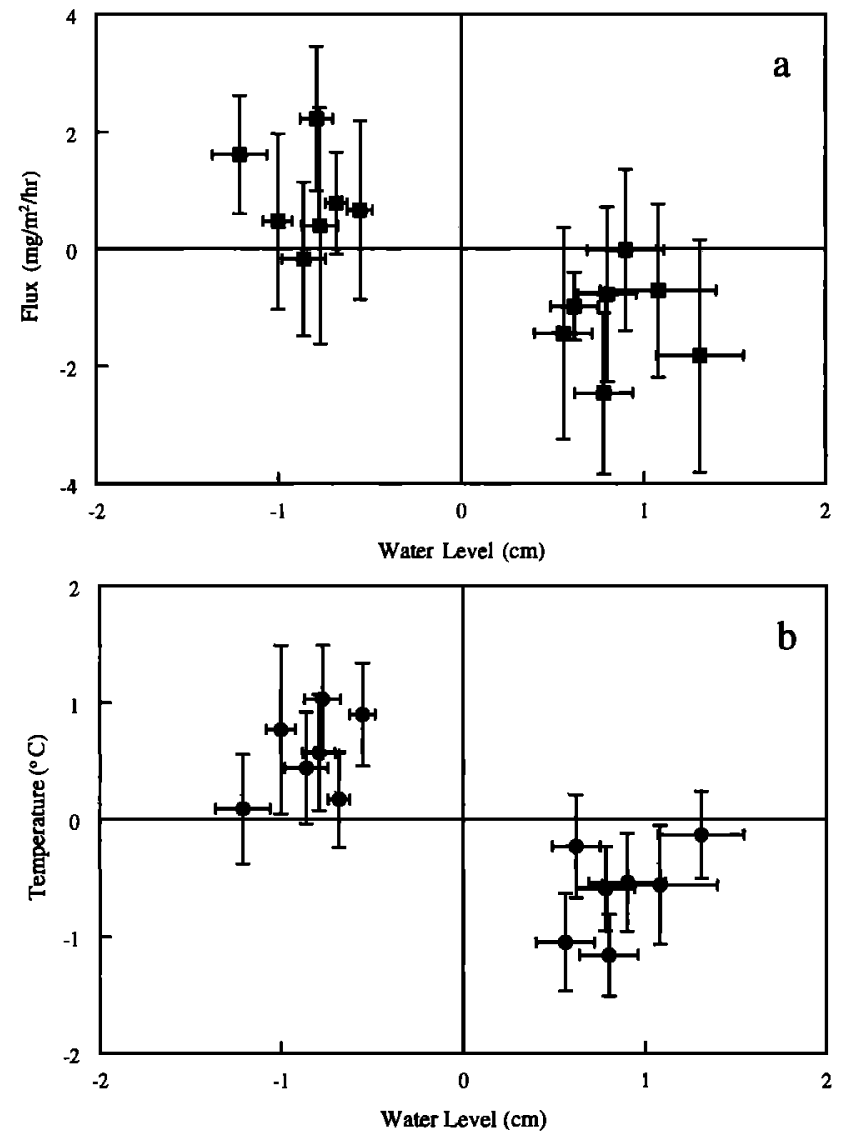

Figure 12. The relationship between water level, soil temperature, and methane emissions. Water level may indirectly affect methane emissions by lowering soil temperature. The fields we studied were inundated throughout the growing season, so these were not subjected to the drying or intermittent flooding that has the opposite effect of shutting off methane emissions.

quite unexpected. We believe that it occurs because of several mechanisms. First, when the fields are flooded with new irrigation water, it is colder than surrounding soil and may cool the soil. Similarly, water added by rain is also likely to cool the soil. Once there is more water in the field, the soil remains cooler because it takes longer for the sun to heat it. Shallow water tends to heat up faster and thus transfer more heat to the soil.

\subsection{Rice Cultivars, Yield, and Fertilizer Applications}

The different rice cultivars have different physiological characteristics that could affect the emission of methane from the fields. Differences of emissions between cultivars were observed in our experiments in Indonesia [Husin et al., 1995]. The work at $\mathrm{Tu} \mathrm{Zu}$ also shows that the rice cultivars may affect methane emissions. Several varieties of common and hybrid rice were planted during the course of our experiments as documented in our earlier paper [Khalil et al., this issue (a)]. We observed that emissions from the hybrid rice were slightly lower than from the regular rice. These results are shown in Figure 13. The variability of the emissions is large enough that it is statistically significant in only 3 of the 7 years. The general pattern, however, is significant also. If there is no difference between hybrid and regular rice, the average difference should be as often negative as it is positive. Five positive results out of six can happen by chance with a probability of less than $2 \%$. 


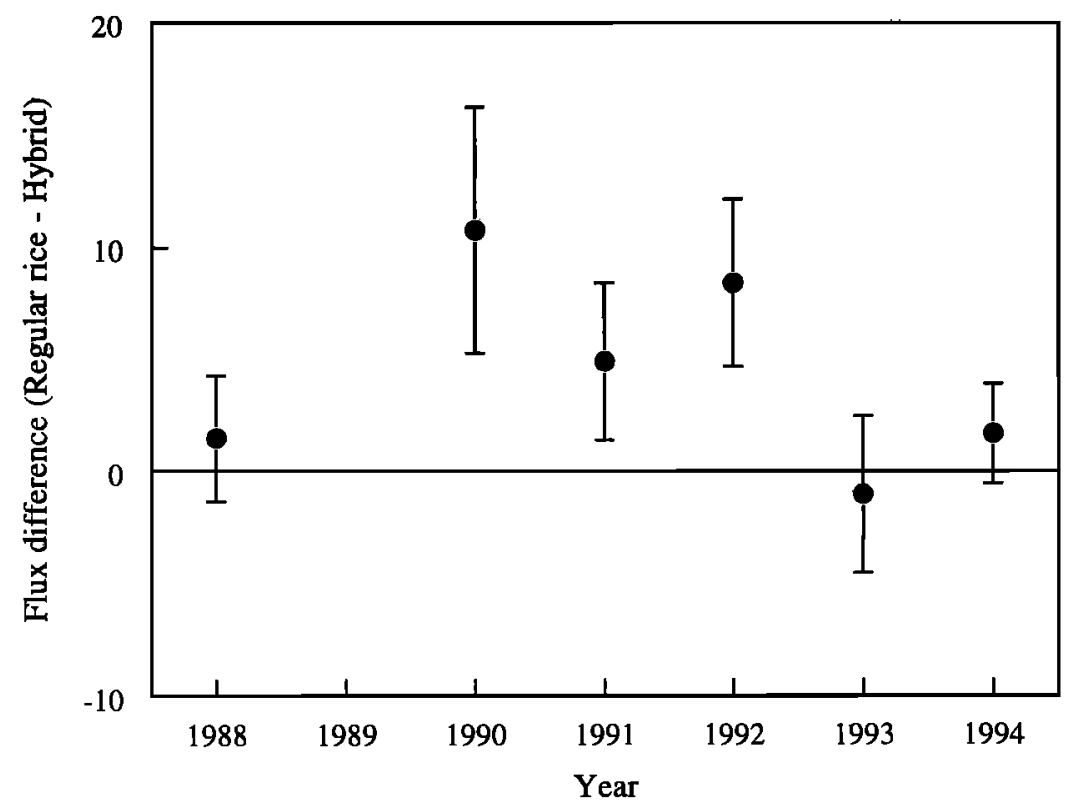

Figure 13. The difference between methane emissions from hybrid rice and regular rice at the rice fields we studied in $\mathrm{Tu} \mathrm{Zu}$, China.

The results of these two studies suggest that rice cultivars can affect methane emissions in the field, but firm conclusions about the causes or which varieties have the potential for greater emissions cannot be deduced from these results. In the Indonesian study, for instance, the hybrid varieties produced more methane than the normal rice, while at $\mathrm{Tu} \mathrm{Zu}$ the hybrid varieties produced less methane. In Indonesia the hybrid rice had more tillers on average than the traditional rice variety but a short growing season, so total methane emission was very similar.

In our studies, methane emissions were not affected by rice yield or by the amount of organic fertilizer applied. These results are shown in Figures 14 and 15 based on the average methane emissions from each field (averaged over all plots within the field).
It is probable that methane emissions from the rice fields we studied have so much organic material and available nutrients that even for the field in which no organic fertilizer was used one year, the methane emissions did not decrease compared to other fields. There appears to be a saturation effect for the emission of methane from rice fields where organic fertilizers are used heavily.

\section{Discussion and Conclusions}

We have considered agricultural and environmental variables that can affect methane emissions from rice fields. We have shown that emissions increase with increasing soil temperature. The response is moderate with $Q_{10} s$ of $2-3$, but as we have noted, there are a

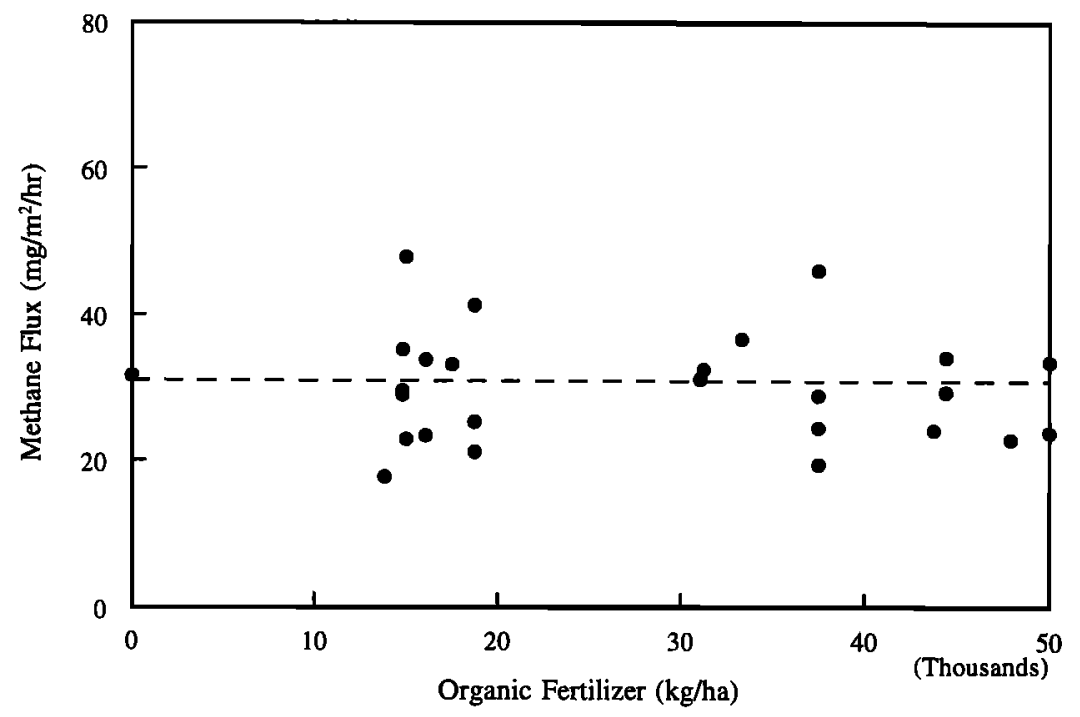

Figure 14. The relationship between methane emissions and amount of organic fertilizer applied. Large amounts of organic fertilizers are used on these fields year after year. It is likely that there is a saturation effect whereby more fertilizer does not further increase the methane flux. The results calculated here are for each of four fields studied over 7 years. 


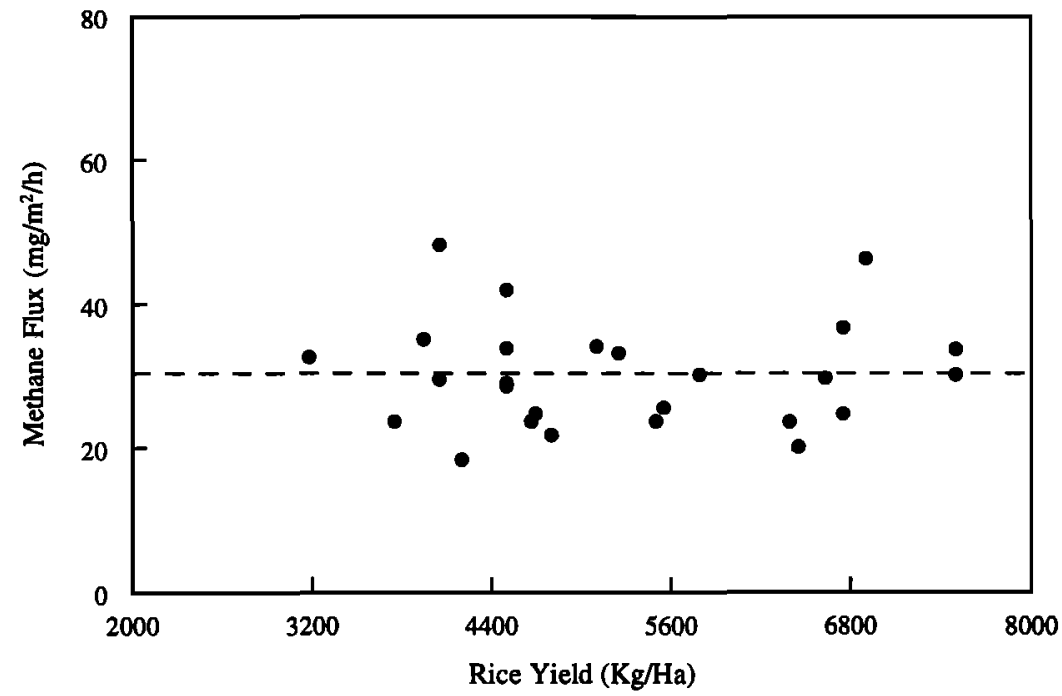

Figure 15. The relationship between methane emissions and rice yield. The hybrid varieties tend to produce slightly less methane and have a higher yield. These differences are small and overshadowed by the observed variability. There is a slight negative relationship, but it is insignificant both in magnitude and statistical certainty. The results calculated here are for each of four fields studied over 7 years.

number of complications that may require a revision of these estimates applied to other locations. The variability of the temperature response from one location to another and the interactions of temperature with other factors that affect methane emissions is still not known. The effect is large enough that further research is warranted. It happens that under present conditions, the soil temperatures in rice growing areas are not very different from one another. The measured average soil temperature in the rice fields ranges from about $23^{\circ} \mathrm{C}$ at Beijing, about $40^{\circ} \mathrm{N}$ latitude, to $25^{\circ}-27^{\circ} \mathrm{C}$ at Guangzhou, and $28^{\circ} \mathrm{C}$ in Indonesia in the tropics. The impact of soil temperature, at different latitudes, for present emissions, is likely to be significant but not dominant as many other factors cause a greater variability of the observed methane flux from one place to another.

We found that planting density has a significant effect on methane emissions. The effect is an increase of emissions by about a factor of 2 when the planting density is increased by a factor of 4 over normal agricultural practices. Changing planting density also affects the seasonal cycle of the emissions as the increase of emission is not uniform over the growing season. These results have important implications for sampling rice fields where rice is planted by broadcast seeding. In that case the density is not as uniform as in the fields where rice is planted in regular rows.

In the fields we studied, there was no observable increase of emissions with increasing organic fertilizer. This is probably caused by the long-term heavy use of organic fertilizers in these fields. The seasonally averaged methane emissions from these fields are among the highest reported from anywhere. We believe that there is a saturation effect for the production and release of methane, so that continued increases in fertilizer applications stops affecting methane emissions.

From the results of this study along with the others that have been published, we estimate that the global emission of methane from rice fields is between 40 and $80 \mathrm{Tg} \mathrm{y}^{-1}$ [Shearer and Khalil, 1993]. Further experiments will help to narrow this range of uncertainty.

Acknowledgments. This project was supported by the U.S. Department of Energy (Michael Riches for his many suggestions and his help with the logistics of carrying out the experiments. We thank Wang Ming-Xing
(IAP), F. Moraes (PSU), and D. Steams (OGI) for their contributions to this project. Additional support was provided by the Biospherics Corporation and the Andarz Co.

\section{References}

Chen, Z., D. Li, K. Shao, and B. Wang, Features of $\mathrm{CH}_{4}$ emission from rice paddy fields in Beijing and Nanjing, China, Chemosphere, 26(1-4), 239246, 1993.

Conrad, R, H. Schütz, and M. Babbel, Temperature limitation of hydrogen turnover and methanogenesis in anoxic paddy soil, FEMS Microbiol. Ecol. 45, 281-289, 1987.

Conrad, R., F. Bak, H.J. Seitz, B. Thebrath, H.P. Mayer, and H. Schutz, Hydrogen turnover by psychrotrophic homoacetogenic and mesophilic methanogenic bacteria in anoxic paddy soil and lake sediment, FEMS Microbiol. Ecol. 62, 85-294, 1989.

Denier van der Gon, H.A.C., and N. van Breeman, Diffusion-controlled transport of methane from soil to atmosphere as mediated by rice plants, Biogeochemistry 21, 177-190, 1993.

Grist, D.H., Rice, $6^{\text {th }}$ edition, 70-73, Longman, New York, 1986.

Hale, M.G., and L.D. Moore, Factors affecting root exudation, II, 19701978, in Advances in Agronomy, vol. 31, 93-124, Academic, San Diego, Calif., 1979.

Hollander, M., and D.A. Wolfe, Nonparametric Statistical Methods, John Wiley, New York, 1973.

Holzapfel-Pschom, A., R. Conrad, and W. Seiler, Effects of vegetation on the emission of methane from submerged paddy soil, Plant Soil, 92, 223233, 1996.

Husin, Y.A., D. Murdiyarso, M.A.K. Khalil, R.A. Rasmussen, M.J. Shearer, S. Sabiham, A. Sunar, and H. Adijuwana. Methane flux from Indonesian wetland rice: The effect, of water management and rice variety., Chemosphere, 31(4), 3153-3180, 1995.

Khalil, M.A.K., M.J. Shearer, and R.A. Rasmussen, Atmospheric methane over the last century, World Resour. Rev. 8(4), 481-492, 1996.

Khalil, M.A.K, R.A. Rasmussen, M.J. Shearer, R.W. Dalluge, L.X. Ren, and C.L. Duan, Measurements of methane emissions from rice fields in China, J. Geophys. Res., this issue (a).

Khalil, M.A.K., R.A. Rasmussen, M.J. Shearer, Z.-L. Chen, H. Yao, and J. Yang, Emissions of methane, nitrous oxide and other trace gases from rice fields in China, J. Geophys. Res., this issue (b).

Khalil, M.A.K., R.A. Rasmussen, and M.J. Shearer, Effects of production and oxidation processes on methane emissions from rice fields, $J$. Geophys. Res., this issue (c). 
Minoda, T., M. Kimura, and E. Wada, Photosynthates as dominant source of $\mathrm{CH}_{4}$ and $\mathrm{CO}_{2}$ in soil water and $\mathrm{CH}_{4}$ emitted to the atmosphere from paddy fields, J. Geophys. Res. 101(D15), 21,091-21,097, 1996.

Nouchi, I., S. Mariko, and K. Aoki. Mechanism of methane transport from the rhizosphere to the atmosphere through rice plants. Plant Physiol., 94:59-66, 1990.

Parashar, D.C., P.K. Gupta, J. Rai, R.C. Sharma, and N. Singh, Effect of soil temperature on methane emission from paddy fields, Chemosphere, 26, 247-250, 1993.

Sass, R.L., F.M. Fisher, F.T. Tumer, and M.F. Jund, Methane emission from rice fields as influenced by solar radiation, temperature, and straw incorporation, Global Biogeochem. Cycles, 5(4), 335-350, 1991.

Sass, R.L., F.M. Fisher, Y.B. Wang, F.T. Tumer, and M.F. Jund. Methane emission from rice fields: The effect of floodwater management., Global Biogeochem. Cycles, 6(3), 249-262, 1992.

Schütz, H., W. Seiler, and R. Conrad, Processes involved in formation and emission of methane in rice paddies, Biogeochemistry, 7, 33-53, 1989a.

Schüt, H., A. Holzapfel-Pschom, R. Conrad, H. Rennenberg, and W. Seiler, A 3-year continuous record on the influence of daytime, season, and fertilizer treatment on methane emission rates from an Italian rice paddy, J. Geophys. Res., 94(D13), 16405-16416, 1989 b.

Schütz, H., W. Seiler, and R. Conrad., Influence of soil temperature on methane emission from rice paddy fields, Biogeochemistry, 11, 77-95, 1990.

Seiler, W., Contributions of biological processes to the global budget of $\mathrm{CH}_{4}$ in the atmosphere, in Current Perspectives in Microbial Ecology, edited by M.J. Klug and C.A. Reddy, pp. 468-477, Am. Soc. for Microbiol., Washington, D. C., 1984.

Seiler, W., A. Holzapfel-Pschorn, R. Conrad, and D. Scharffe, Methane emission from rice paddies, J. Atmos. Chem., 1, 241-268, 1984.

Shearer, M.J., and M.A.K. Khalil, Rice agriculture: Emissions, in
Atmospheric Methane: Sources, Sinks, and Role in Global Change, NATO ASI Ser. I, vol. 13, edited by M.A.K. Khalil, 230-253, SpringerVerlag, New York, 1993.

Snedecor, G.W., and W.G. Cochran, Statistical Methods, $8^{\text {th }}$ ed., Iowa State Univ. Press, Ames, 1989.

United Nations, FAO Production Yearbook, vols. 30-47, Food and Agric. Org. of the U. N., Rome, 1977-1994.

Westermann, P., Temperature regulation of methanogenesis in wetlands, Chemosphere 26(1-4), 321-328, 1993.

Yagi, K., H. Tsuruta, K. Kanda, K. Minami, Effect of water management on methane emission from a Japanese rice paddy field: Automated methane monitoring, Global Biogeochem. Cycles, 10(2), 255-267, 1996.

Yao H., and Z.L. Chen, Effect of chemical fertilizer on methane emission from rice paddies, J. Geophys. Res. 99(D8), 16,463-16,470, 1994a.

Yao H., and Z.L. Chen, Seasonal variation of methane flux from a Chinese rice paddy in a semi arid, temperate region, J. Geophys. Res. 99(D8), $16,471-16,477,1994 b$.

R.W. Dalluge and R.A. Rasmussen, Department of Environmental Science and Engineering, Oregon Graduate Institute, P.O. Box 91000, Portland, OR 97291.

C.L. Duan, Institute of Mountain Disasters and Environment, P.O. Box 417, Chengdu, Sichuan 619941, People's Republic of China.

M.A.K. Khalil and M.J. Shearer, Department of Physics, Portland State University, P.O. Box 751, Portland, OR 97207-0751. (e-mail: aslam@atmos.phy.pdx.edu).

L.X. Ren, Institute of Atmospheric Physics, Academia Sinica, Beijing 100029, People's Republic of China.

(Received July 29, 1997; revised February 17, 1998; accepted March 31, 1998.) 